\title{
Coexistent mitral and aortic valve atresia with intact ventricular septum in sibs
}

\author{
Per G. Bjørnstad ${ }^{1}$ and Helge Michalsen ${ }^{2}$ \\ From the Department of Pediatric Cardiology, Rikshospitalet, Oslo, and the Department of Paediatrics, \\ Porsgrunn Luth Sykehus, Porsgrunn, Norway
}

The first instance of 2 sibs with coexistent mitral and aortic valve atresia with intact ventricular septum is reported. No definite aetiology could be detected, though Coxsackie B virus antibodies were found in the mother's serum.

$A$ review of the reports on similar cases showed no male preponderance (50\%). In contrast, the heterogeneous group of hypoplastic left heart syndrome showed 64 per cent male preponderance.

The mean maternal age was 31 years in hypoplastic left heart syndrome, excluding patients with interruption of the aortic arch and mitral and aortic valve atresia where the mean maternal age was lower, 22 and 26 years, respectively.

The group with mitral and aortic valve atresia should be considered as a separate entity from the group with hypoplastic left heart syndrome and may be a genetic disorder.

Hypoplastic left heart syndrome was originally defined and classified by Lev (1952). Since then it has become increasingly apparent that this syndrome is an inhomogeneous complex which should be rearranged according to aetiological, haemodynamic, and anatomical features of the various malformations.

Despite numerous reports on hypoplastic left heart syndrome, little has been published on coexistent mitral and aortic valve atresia with an intact ventricular septum. The published reports up to 1972 contain only 35 definite cases (Philpott, 1928; Walker and Klinck, 1942; Newerla, 1944; Friedman, Murphy, and Ash, 1955; Lumb and Dawkins, 1960; Kanjuh, Eliot, and Edwards, I965; Alberman, Fedrick, and Schutt, 1967; Apitz and Stoermer, 1967; Hunter and Nichols, 1968; Saied and Folger, 1972) if the disease is defined as follows. A: mitral valve atresia; $B$ : aortic valve atresia; C: intact ventricular septum; D: cavity of left ventricle identified; and $\mathrm{E}$ : persistent ascending aorta.

This condition has not previously been described in sibs, but familial occurrence of other forms of

Received 27 July 1973.

1 Present address: Cardiology Division, Paediatric Clinic, University of Göttingen, Göttingen, Western Germany.

2 Present address: Department of Paediatrics, Ullevảl Hospital, Oslo, Norway. hypoplastic left heart syndrome has been reported by Ehlers and Engle (1966), Kojima et al. (1969), Rao, Gootman, and Platt (1969), and Saied and Folger (1972).

\section{Case reports}

\section{Case I}

A girl was born on 9 August 1970 after a normal first pregnancy. Birthweight was $3 \cdot 4 \mathrm{~kg}$ and length $52 \mathrm{~cm}$. The Apgar score was ro after I minute. During the first 36 hours her condition was good. The routine examination by a paediatrician revealed no abnormalities. At the age of 36 hours she became cyanosed and grey with rapid shallow respiration. Though she was placed in an incubator and received oxygen, her condition deteriorated. On clinical examination of the heart and lungs there was no suspicion of heart disease, but the liver was enlarged, reaching the umbilicus. Inguinal pulses were not detectable. A metabolic acidosis with $p \mathrm{H} 7 \cdot \mathrm{I} 4$ and $\mathrm{PCO}_{2}$ I $7 \mathrm{mmHg}$ was found. Oxygen saturation in capillary blood was 64 per cent, $\mathrm{Hb}$ was $19^{\circ} \mathrm{O}$ $\mathrm{g} / \mathrm{I} 00 \mathrm{ml}$, and haematocrit $6 \mathrm{I}$ per cent.

Intravenous infusion with glucose 5.5 per cent was initiated. The acidosis was corrected by bicarbonate. Antibiotics were administered intravenously. Suspecting some inborn error of metabolism as the cause of the metabolic acidosis, an exchange transfusion was carried out. Her condition steadily worsened and she succumbed in a state of cardiac failure at the age of 44 hours. 


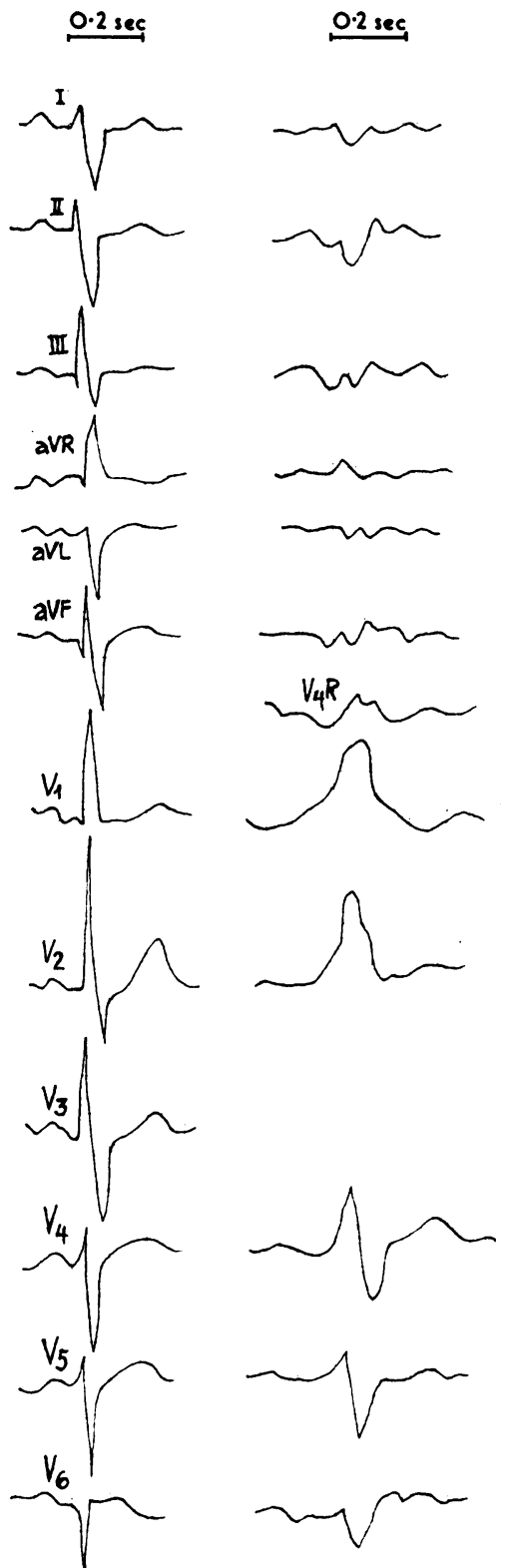

FIG. I Electrocardiogram of Case 2 at 36 and 45 hours of age, the former demonstrating a mean frontal plane $Q R S$ axis of $-170^{\circ}$ and a right ventricular hypertrophy, the latter showing a fully developed right bundle-branch block.

\section{Case 2}

The parents' second child was a girl born on 29 September I97I after a normal pregnancy and delivery. Birthweight was $3.2 \mathrm{~kg}$, length $5 \mathrm{I} \mathrm{cm}$, and Apgar score
Io after I minute. After satisfactory development in the first 24 hours, gradually increasing cyanosis was noted. With her sister's heart disease in mind, a thorough examination of the heart and lungs revealed normal findings except for tachypnoea without retraction. Inguinal pulses were present. During the next few hours her condition rapidly deteriorated, with increasing cyanosis. By 38 hours of age the liver reached the umbilicus. She had a slight acidosis. Deslanocid was administered intravenously, and she was transferred to the Children's Hospital, Rikshospitalet, Oslo.

On arrival she was 42 hours of age, had mild central cyanosis, and a respiratory rate of roo a minute with slight subcostal retraction. Capillary blood showed severe acidosis with $p \mathrm{H} 6.65$ and an oxygen saturation of 50 per cent. The patient was placed in an incubator with high oxygen concentration. Deslanocid was continued. An attempt to correct the acidosis with sodium bicarbonate and THAM was unsuccessful, and she died at the age of 48 hours.

\section{Cardiological examination}

Only Case 2 was subjected to cardiological examination as in Case I there had been no suspicion of heart disease. In Case 2 there was initially no murmur, but 40 hours

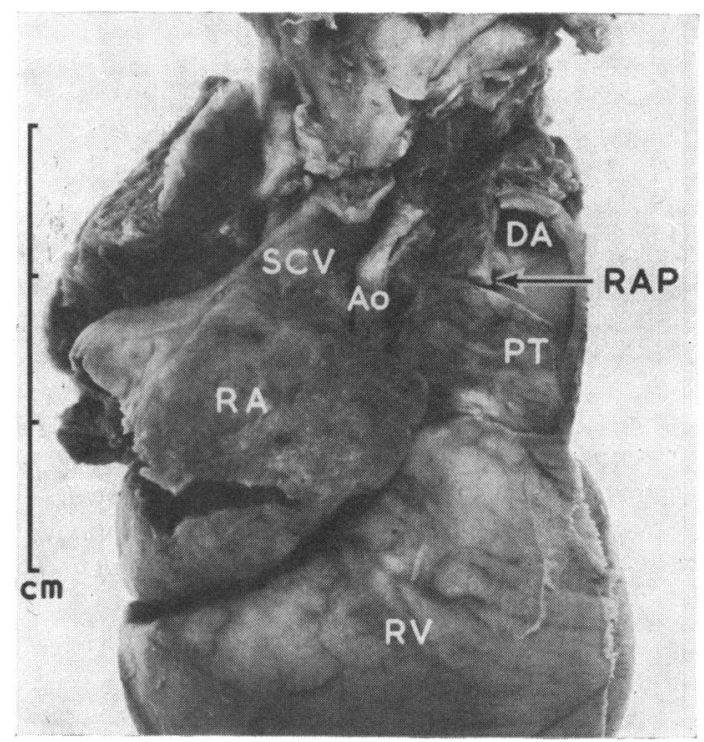

FI G. 2 Heart of Case I in the anterior view showing the greatly dilated right atrium, the huge pulmonary artery, and the thin aorta of a probe's size. Abbreviations Fig. 2-4: Ao, aorta; ALPM, anterolateral papillary muscle; $D A$, ductus arteriosus; $L A$, left atrium; $L A A$, left atrial appendage; LPA, left pulmonary artery; $L V$, left ventricle; $M V$, mitral valve; $P M P M$, posteromedial papillary muscle; $P$ T, pulmonary trunk; $R A$, right atrium; $R P A$, right pulmonary artery; $R V$, right ventricle; $S C V$, superior caval vein. 


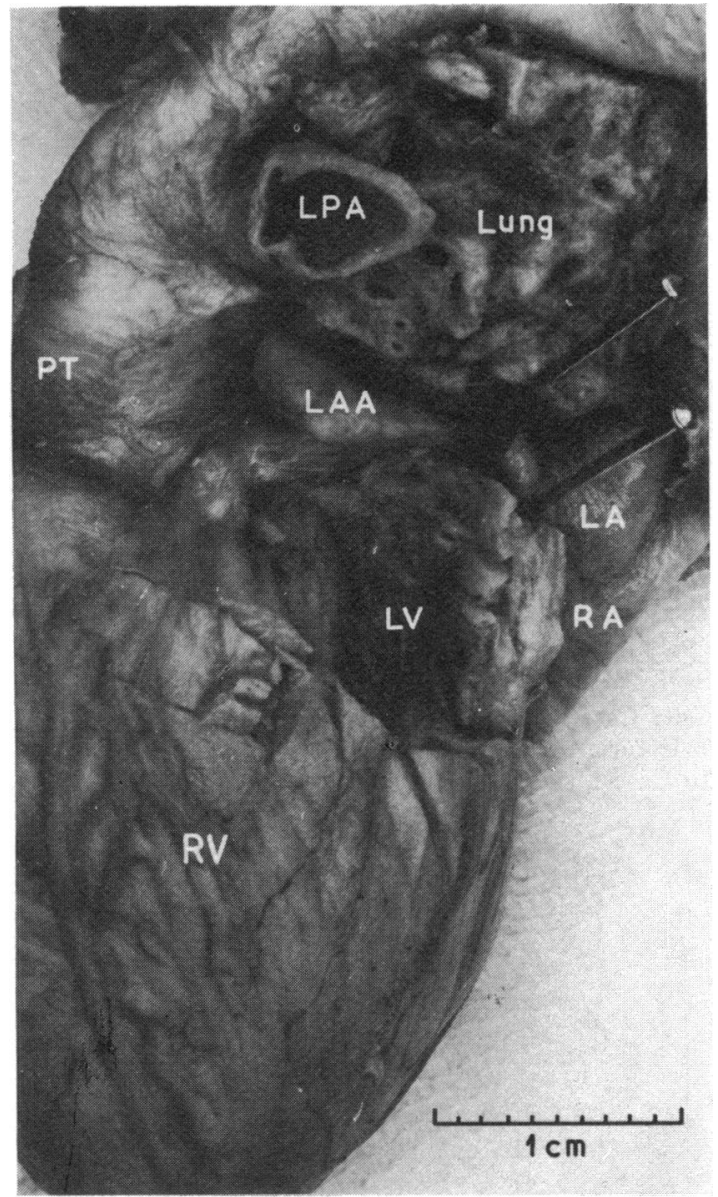

FIG. 3 Heart of Case I viewed from the left. The left ventricular wall is lifted by pins. The rest of the ventricular mass is made out of the right ventricle, whick gives rise to the huge pulmonary trunk. Note the distribution of the coronary artery, a sign that the left ventricle must be there.

after birth a systolic murmur of grade $3 / 6$ was heard in the 2nd and 4th left intercostal spaces. The electrocardiogram showed a pronounced right axis deviation of $-170^{\circ}$ and hypertrophy of the right ventricle (Fig. I). Three hours before death an electrocardiogram revealed complete right bundle-branch block (Fig. I). $X$-rays of the heart showed an enlarged heart, a large pulmonary artery, and pulmonary plethora. Cardiac catheterization revealed very high pressures in the right atrium (2r/10 mean $14 \mathrm{mmHg}$ ). Further studies were not performed because she developed severe bradycardia, and died shortly afterwards.

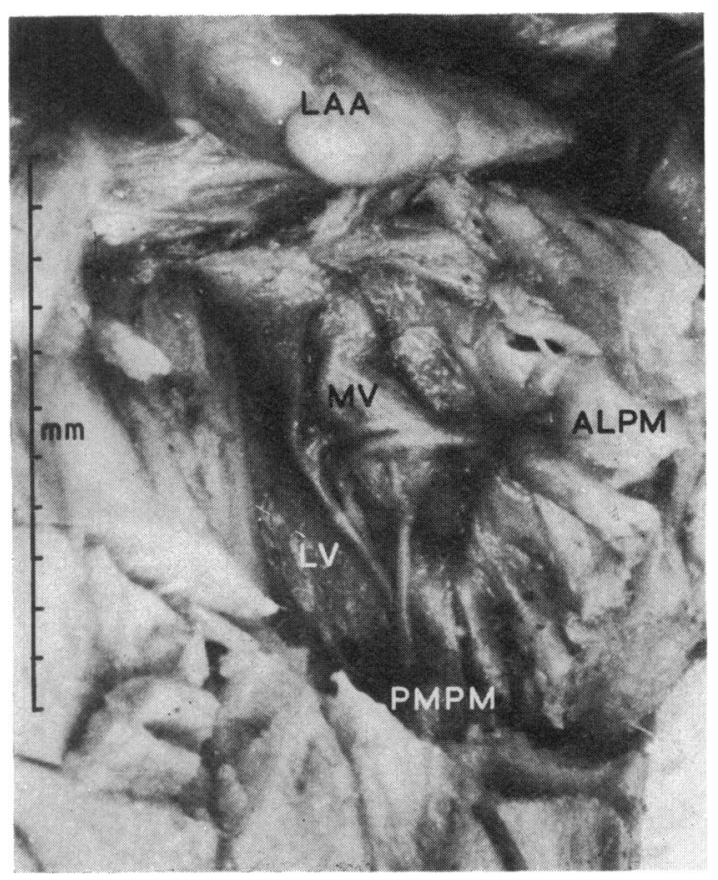

FIG. 4 Close-up of the left ventricular cavity showing the mitral valve leaflets with their chordae tendineae and the anterolateral and posteromedial papillary muscles. The outflow tract of the left ventricle hides in the shadow to the upper left in the ventricular cavity (Case I).

\section{Necropsy}

The abnormal findings were confined to the cardiovascular system and those changes explicable by the abnormal haemodynamics in both cases. The cardiac findings were as follows.

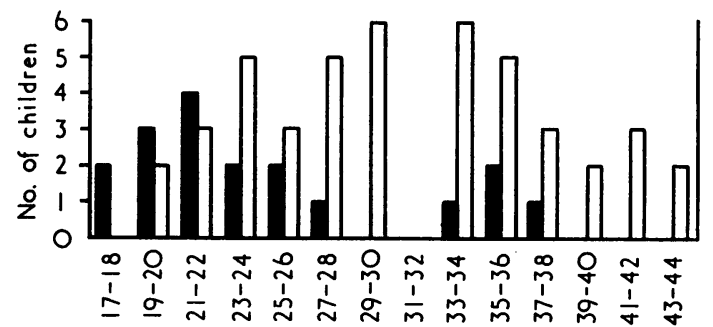

Maternal age at birth of affected child

FIG. 5 Distribution of maternal age at birth of affected child in hypoplastic left heart syndrome (white columns) and mitral and aortic valve atresia (black columns), mean 31 and 24.9 years, respectively. The latter group differs significantly from the former group $(\mathrm{P} \leqq 0 \cdot 001)$. 
Case I The right ventricle and atrium were greatly hypertrophic and enlarged (Fig. 2), the wall thicknesses measuring $6 \mathrm{~mm}$ and $2 \mathrm{~mm}$, respectively. The aortic valve was atretic. The left ventricular cavity was extremely small, only $8 \mathrm{~mm}$ in length and contained clotted blood (Fig. 3). The interventricular septum was intact. The mitral orifice was atretic with a membrane across it, but the valve could be identified with its chordae tendineae and the papillary muscles (Fig. 4). The left atrium was small. The septum primum was redundant, probably creating an obstruction to the rightto-left shunt through the foramen ovale during fetal life. Thus, the small but patent foramen ovale was difficult to reach and to pass with a probe. The left, and to a lesser extent the right, venous (sinoatrial) valves were more prominent than usual. A much dilated pulmonary trunk communicated with the aorta through a patent ductus, which may have been in the process of closing. There was slight hypoplasia of the transverse aortic arch and pronounced hypoplasia of the ascending aorta (Fig. 2), which functioned as a 'common coronary artery', since blood flow through it was retrograde and perfused the coronaries only. The relative position of the great vessels was normal.

Case 2 Sister of Case I. In this case it was impossible to identify a mitral valve or the papillary muscles in the blind left ventricular cavity. The mitral valve atresia was more muscular than in Case $I$. The septum primum did not appear redundant and obstructive, and the venous (sinoatrial) valves were normal. The heart weight was $22 \mathrm{~g}$, mural thickness of the right atrial and ventricular walls being $2 \mathrm{~mm}$ and $5 \mathrm{~mm}$, respectively. In other respects the findings were identical with those in Case $I$.

\section{- Family history and examination of parents}

The parents were unrelated, the mother was 18 and the father 23 years of age at the first delivery. A niece and a nephew of the patients' paternal grandfather both died during or shortly after birth. In neither case was there evidence of congenital heart disease. The family history, which was thoroughly investigated, gave no further evidence of children with early death in the past 50 years, nor did it give any information about heart disease in the adult members of the family.

Cardiological examination of the parents was negative. The patients' mother, repeatedly questioned, gave no information that she might have been exposed to any known teratogenic influence during the pregnancies.

\section{Genetic and viral studies}

Leucocyte cultures from the mother and father, as well as leucocyte and fibroblast cultures from Case 2, did not reveal any chromosome aberrations.

Studies for virus antibodies in the mother's serum showed no evidence of past infection with cytomegalus virus or rubella virus. There was, however, a titre of antibodies against varicella/zoster of 5 , against Coxsackie -B virus (types I, 4, 5, 6) of Io, and against Coxsackie B virus (types 2 and 3 ) of 20 . No virus was isolated from the mother's faeces.

\section{Discussion}

The hypoplastic left heart syndrome is considered to affect more males than females. Summarizing the cases of Noonan and Nadas (1958), Cloup et al. (1970), Saied and Folger (1972) excluding those cases with mitral and aortic valve atresia, and the cases of Alberman et al. (1967) excluding both these cases and the patients with interruption of the aortic arch, 102 of 160 are boys (64\%).

Watson and Rowe (1962) and Apitz and Stoermer (1967) found $35 / 59$ boys (59\%) in patients with aortic valve atresia Some of these probably had mitral and aortic atresia, but cannot be excluded.

There is, however, no reported male preponderance in the published material concerning the special subgroup which is the subject of this paper. Indeed, including our two cases, only II of a total of 22 patients where the sex is indicated have been boys $(50 \%)$. This might indicate that in mitral and aortic valve atresia the sex-linked factors are of less aetiological importance.

The concept that genetic factors influence the aetiology of congenital heart disease has been supported by Nora et al. (1967), Emanuel (1970), and Jörgensen (1970). German, Ehlers, and Engle (1966) have shown chromosome aberrations in some of their patients with congenital heart disease and their relatives. Of the mothers of patients with mitral and aortic valve atresia, 23 have given birth to at least 63 children. Two of these mothers have borne more than one child with congenital heart disease, and Saied and Folger (1972) also report another patient with mitral and aortic valve atresia with two affected relatives.

Although the family history in our two cases gave no evidence of other cases of congenital heart disease, the occurrence of two almost identical cases of mitral and aortic valve atresia in the two sibs, supports the view that there is a hereditary component in the aetiology of these heart defects.

In their analysis of 50 cases of hypoplastic left heart syndrome, Alberman et al. (1967) found the mean maternal age significantly above average (3I years), excluding mitral and aortic valve atresia and patients with an interruption of the aortic arch. Mean maternal age in the latter was 22 years.

In the 18 reported cases of mitral and aortic valve atresia where we know the maternal age, the mean age was 24.9 years (Fig. 5). This differs significantly from the mean maternal age in hypoplastic left heart syndrome, as reported by Alberman et al. (1967) (by the Wilcoxon two-samples-test $\mathbf{P} \leqq 0.0013)$. Thus, the mean maternal age is another area where mitral and aortic valve atresia differs from other types of hypoplastic left heart syndrome; 
this helps to justify the view that it is a disease sui generis.

Burch et al. (1966) and Brown and Evans (1967) reported Coxsackie virus aetiology of congenital heart disease on the basis of endocarditis and valvulitis during fetal life. The mother of our patients was found to have antibodies against two groups of Coxsackie B virus, and though no virus could be isolated she may have infected both infants during fetal life. Microscopy of the heart specimen did not support this theory. The fused mitral cusps in Case I could possibly represent sequelae of valvulitis. Such fused mitral valves have previously been observed only once in mitral and aortic valve atresia (Hunter and Nichols, 1968).

\section{Conclusion}

Familial occurrence of mitral and aortic valve atresia has previously not been reported. However, there have been several reports of other complicated congenital heart disease in the immediate or more distant family members of some cases. Investigations for possible aetiological factors have not provided definite evidence. These additional familial cases appear to support the suspicion of a genetic cause or influence on the aetiology of the disease. In several respects the present malformation differs from other types of hypoplastic left heart syndrome and appears to be a separate entity.

Our thanks are due to Dr. Richard van Praagh, Director of Cardiac Pathology and Embryology at the Children's Hospital Medical Center, Boston, Massachusetts, U.S.A., for willing and kind help in reviewing the pathology of the present cases.

\section{References}

Alberman, E. D., Fedrick, J. M., and Schutt, W. H. (I967). Hypoplastic left heart complex. Fournal of Medical Genetics, 4,83 .

Apitz, J., and Stoermer, J. (1967). Klinik und Pathologie der Aortenatresie. Monatsschrift für Kinderheilkunde, 115, 365.

Brown, G. C., and Evans, T. N. (1967). Serologic evidence of Coxsackievirus etiology of congenital heart disease. Fournal of the American Medical Association, 199, 183.
Burch, G. E., DePasquale, N. P., Sun, S. C., Hale, A. R., and Mogabgab, W. J. (1966). Experimental coxsackievirus endocarditis. Fournal of the American Medical Association, I96, 349.

Cloup, I., Cloup, M., Fournet, J.-P., and Marie, J. (1970). Syndrome d'hypoplasie du coeur gauche. Annales de Pédiatrie, 17, 722.

Ehlers, K. H., and Engle, M. A. (1966). Familial congenital heart disease. Circulation, 34, 503.

Emanuel, R. (1970). Genetics and congenital heart disease. British Heart fournal, 32, 281.

Friedman, S., Murphy, L., and Ash, R. (1955). Congenital mitral atresia with hypoplastic nonfunctioning left heart. American fournal of Diseases of Children, 90, 176.

German, J., Ehlers, K. H., and Engle, M. A. (I966). Familial congenital heart disease. Circulation, 34, 517.

Hunter, D. T., and Nichols, M. M. (1968). Mitral and aortic atresia with a blind left ventricle. Vascular Surgery, 2, 194.

Jörgensen, G. (1970). Twin studies in congenital heart diseases. Acta Geneticae Medicae et Gemellologiae, 19, 25 I.

Kanjuh, V. I., Eliot, R. S., and Edwards, J. E. (1965). Coexistent mitral and aortic valvular atresia. American fournal of Cardiology, 15, 6 I r.

Kojima, H., Ohgimi, Y., Mizutani, K., and Nishimura, Y. (1969). Hypoplastic-left-heart-syndrome in siblings. Lancet 2, 70I.

Lev, M. (1952). Pathologic anatomy and interrelationship of hypoplasia of the aortic arch complexes. Laboratory Investigation, $\mathrm{I}, 6 \mathrm{r}$.

Lumb, G., and Dawkins, W. A. (1960). Congenital atresia of mitral and aortic valves with vestigial left ventricle. American Heart fournal, 60, 378.

Newerla, G. J. (1944). Associated mitral and aortic atresia or hypoplasia. Archives of Pediatrics, 6r, 68.

Noonan, J. A., and Nadas, A. S. (I958). The hypoplastic left heart syndrome: an analysis of ror cases. Pediatric Clinics of North America, 5, 1029.

Nora, J. J., Campbell Gilliland, J., Somerville, R. J., and McNamara, D. G. (1967). Congenital heart disease in twins. New England fournal of Medicine, 277, 568.

Philpott, N. (1928). Congenital atresia of aortic ring. Annals of Internal Medicine, 2, 422.

Rao, S. S., Gootman, N., and Platt, N. (1969). Familial aortic atresia. American fournal of Diseases of Children, II8, 919.

Saied, A., and Folger, G. M. (1972). Hypoplastic left heart syndrome. American fournal of Cardiology, 29, 190.

Walker, R., and Klinck, G. H. (1942). Congenital aortic and mitral atresia. American Heart fournal, 24, 752.

Watson, D. G., and Rowe, R. D. (1962). Aortic-valve atresia. Fournal of the American Medical Association, 179, I4.

Requests for reprints to Dr. P. G. Bjørnstad, Cardiologic Division, Paediatric Clinic, University of Göttingen, Göttingen, West Germany. 